\title{
Assessment of environmental conditions in Civitavecchia (Rome, Italy) harbour
}

\author{
G. Zappalà ${ }^{1,2}$, V. Piermattei ${ }^{2}$, A. Madonia ${ }^{2}$, R. Martellucci ${ }^{2}$, \\ S. Bonamano ${ }^{2}$, A. Pierattini ${ }^{2}$, C. Burgio ${ }^{3} \&$ M. Marcelli ${ }^{2}$ \\ ${ }^{1}$ Istituto per l'Ambiente Marino Costiero (IAMC), \\ National Research Council, Messina, Italy \\ ${ }^{2}$ DEB Experimental Oceanology and Marine Ecology Laboratory, \\ Tuscia University, Italy \\ ${ }^{3}$ Environmental Office Port Authority of the ports of Rome and Lazio, \\ Civitavecchia, Italy
}

\begin{abstract}
Harbours and maritime transport are essential for both local and national economic development creating wealth, jobs and attracting investment and resources. However, the presence of port infrastructures and associated activities such as vessel docking, handling and transport of goods, production of a great quantity of wastes and pollutants and periodical dredgings, generate significant environmental impacts on coastal ecosystems and seawater quality. Civitavecchia harbour (Rome, Italy) is the first Mediterranean cruise port with approximately 2.6 million passengers, characterized by intense traffic of ships engaged in the carriage of goods and persons and interested by continuous maintenance and expansion works to improve its receptive capacity. In this context a significant support is given from the availability of continuous measurement systems, which offer an important tool for marine monitoring, allowing the acquisition of physical, chemical and biological time series, fundamental prerogative to promptly verify any unexpected phenomena and process. The Laboratory of Experimental Oceanology and Marine Ecology (University of Tuscia) is strongly involved in the environmental monitoring of the Civitavecchia coastal area. In June 2012 a fixed station was installed on a dock of the Civitavecchia harbour performing repeated measurements of surface water temperature, conductivity, dissolved oxygen, $\mathrm{pH}$, turbidity and chl- $a$ fluorescence. Moreover, a weather station acquiring meteorological parameters
\end{abstract}


(wind speed and direction, precipitation, atmospheric pressure, air temperature and humidity and solar radiation), a surface buoy, moored outside the Civitavecchia harbour, and in situ water samplings provided data comparable with the fixed station. In support of the system a high resolution hydrodynamical model was used to calculate current and waves parameters around and inside the harbour area, allowing us to analyse the conservative constituents (e.g. suspended solids) behaviour. At the end of 2012 considerable modifications were made on the harbour structures, concerning Colombo breakwater extension and new Dock Services. The present work reports the observations on main water parameters before and after the cited works, comparing them with the results of model simulations.

Keywords: harbour seawater quality, coastal monitoring, mathematical models.

\section{Introduction}

Port activities are fundamental nodes for logistics and economical development of coastal areas, providing the main link between sea and land human activities (exchanges of goods, passengers, resources, etc.). Both local and national administrations benefit the presence of harbour infrastructures, which represent a great source of wealth and jobs, attracting investment and resources. Besides, port facilities strongly modify the natural conditions of the coastal areas in which they are located, since the discharge of contaminated sewage waters could severely compromise the quality of harbour marine waters. Moreover, manufacturing and harbour activities including dredging, reclamation, construction and shipping are reported to cause impacts such as high sediment load, re-suspension of particulate heavy metals, organic pollution, etc. [1, 2].

The protection of aquatic ecosystems is a prerogative of 2008/56/EC Marine Strategy Framework Directive (MSFD), aimed at the reduction of pollution sources and prevention of pollution risks to the marine environments, in order to prevent any significant impacts or risks to marine biodiversity, marine ecosystems and human health.

Within this context, a continuous monitoring of harbour water quality is fundamental for the adoption of correct intervention strategies targeted to reduce the environmental risks related with the spreading of pollutants on the surrounding areas. This provides a complete picture of the health status of a specific environment and allows us to assess whether its conditions evolve towards improvement, worsening, or are stable. Advanced technologies have been developed in the years to allow low-cost real time monitoring [3-13]. The use of mathematical models is suggested to get integrated responses about the level of contamination and pollution in marine ecosystems; models may in fact offer an useful tool for early warning of pollution phenomena, enabling local authorities to set up suitable measures to protect areas which are most threatened $[14,15]$. In this framework, the Port Authority of Civitavecchia has set up an environmental observational network composed by fixed stations for marine water quality and weather monitoring, in situ water and sediment sampling stations. To this network belongs also a platform deployed in 2012 about a mile 
southern the port of Civitavecchia hosting a data acquisition and transmission system for continuous measurement of temperature, conductivity, dissolved oxygen, $\mathrm{pH}$, turbidity and chlorophyll a fluorescence [16].

Moreover, at the end of 2012, Civitavecchia harbour has undergone a series of modifications, the most important of which was the Cristoforo Colombo embankment extension. This engineering work has resulted in a change of the dynamic conditions of the port. The objective of this study is to provide time series of a full set of the main water parameters measurements in order to estimate the potential effects of the harbour structural modifications.

This study is based only on the measurement stations installed inside the port; to assess the changes occurred in the basin after the embankment extension.

\section{Materials and methods}

\subsection{Study area}

Thanks to its strategical position on the Tyrrhenian Sea, Civitavecchia harbour (Rome, Italy) is the first Mediterranean cruise port with approximately 2.6 million passengers. In the last fifteen years, the continuous maintenance and expansion works has greatly enhanced its receptive capacity, allowing the increase of traffic of ships engaged in the carriage of both goods and persons. The port is configured as a multi-functional structure divided into two main areas: a southern one dedicated to tourism, yachting and cruises, the northern one to commercial traffic, fishing and coastal shipping (Fig. 1).

The port comprises $17 \mathrm{~km}$ of piers, 2 million square meters of yards, it has an average depth of 16 meters and the availability of more than 5 million square feet of back areas; it usually hosts cruise ships having an average size of 300 meters, a tonnage of about 95.000 tonnes and transporting up to 3,000 guests.

Due to the continuous increasing of transport and commercial activities the Civitavecchia harbour needed to improve its structure. In this context also the monitoring network was implemented through the installation of a water quality station and the improvement of the meteorological one.

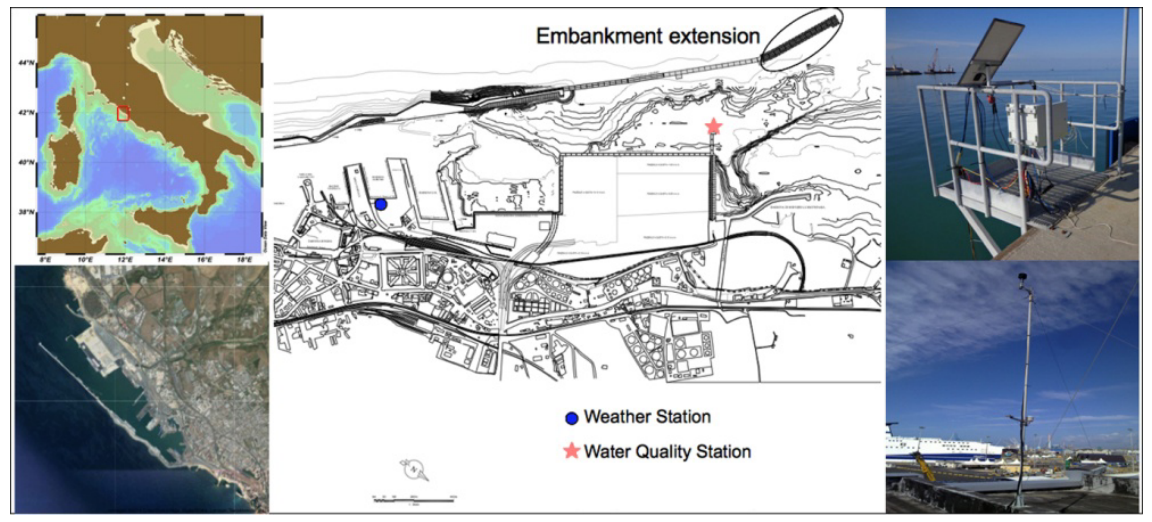

Figure 1: $\quad$ Study area; on the right, the fixed stations. 


\subsection{Fixed stations}

\subsubsection{Water quality station}

A fixed station was installed on a dock of the Civitavecchia harbour to measure surface temperature, conductivity, $\mathrm{pH}$, dissolved oxygen, chlorophyll $a$ fluorescence and turbidity. The system was designed to collect data every 20 minutes and to transmit twice a day all the data to the Laboratory using a cellular modem. An accurate work of chlorophyll- $a$ fluorescence and turbidity data calibration was performed through a periodical seawater sampling. Seawater for pigment analysis was also pre-filtered by a net of $250 \mu \mathrm{m}$ to remove zooplancton and macroalgae. Both samples for Chlorophyll- $a$ and Total Suspended Matter (TSM) measurements were stored in dark bottles. Known volumes of water samples were collected on $\mathrm{GF} / \mathrm{F}$ glass-fibre filters and pigment extracted at $4{ }^{\circ} \mathrm{C}$, for at least $24 \mathrm{~h}$ in $90 \%$ acetone. Measurements were carried out using a Shimadzu spectrophotometer "UV mini 1240" model. TSM water samples were collected on pre-dried and pre-weighed GF/C glass-fibre filters; analyses were carried out following the gravimetric method.

\subsubsection{Weather station}

The Port Authority weather station, placed in Civitavecchia harbour at 20 meters height, provided data of temperature, wind speed and direction, atmospheric pressure, rainfall and solar radiation every 10 minutes. The weather station consisted of the following devices: Vaisala HMP5 (temperature and humidity), WindSonic 2-Axis Ultrasonic Anemometer Range (wind speed and direction), Vaisala PTB101B (barometric pressure), Texas Electronics TE525MM (rain gage) and LICOR LI200X (solar radiation).

\subsection{Mathematical models}

To analyse the marine current, the wave propagation toward the coast and the dispersion of sediment particles inside and around the harbour area twodimensional mathematical models, like ADCIRC, STWAVE and PTM, that are included in the SMS 11.1 (Surface-water Modelling System), were applied.

The ADvanced CIRCulation model (ADCIRC) [17] is a two-dimensional, depth-integrated, barotropic time-dependent long wave, hydrodynamic circulation model that utilizes a finite element grid to calculate the marine currents due to wind stress.

The STeady-state spectral WAVE (STWAVE) [18] is a finite-difference, phase averaged spectral wave model that accurately simulates nearshore wave propagation and transformation including refraction, shoaling, breaking, and wind-wave generation.

The hydrodynamic and wave fields calculated by ADCIRC and STWAVE model, as well as the granulometry and density of the marine sediment found inside the Civitavecchia port, were used as input conditions in Lagrangian-based Particle Tracking Model (PTM) [19] to estimate the percentage of suspended and settled sediment particles in the study area. 
The model results were used to support the physical, chemical and biological time-series analysis acquired by a fixed station mounted at a depth of $5 \mathrm{~m}$ on the seaward side of the pier 26.

In this study the mathematical models were employed to evaluate the effects of the new harbour structures on the wave and current fields and, consequently, on the sediment particles dispersion. Since the physical processes inside and around the harbour have micro temporal and spatial scales, very high resolution grids were needed. So ADCIRC finite element mesh had high spatial resolution $(\Delta \mathrm{x} \sim 10 \mathrm{~m})$ near the harbour structures and along the coast between the port entrance and the ENEL Power Plant. The finer element size was applied to STWAVE finite difference grid in the entire model domain.

To simulate the current velocity and the wave propagation toward the coast, wind data collected by Port Authority weather station and wave parameters (significant wave height Hs, peak period Tp and mean direction Dir) calculated by WAM model [20] at the point with coordinates: Lat. $42.10 \mathrm{~N}$ and Long. 11.70 E were employed.
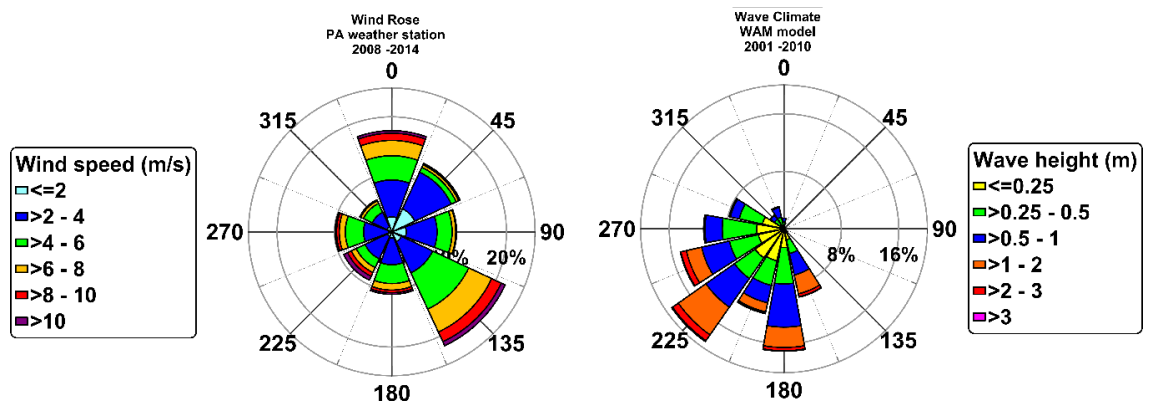

Figure 2: Wind rose (left) and wave climate (right) obtained from Port Authority data (2008-2014) and from WAM model (2001-2010) at point located off the coast of Civitavecchia, respectively.

Considering the coastline orientation in the study area, the more significant events to study the main patterns of the coastal dynamic around and inside the harbour zone come from third and the fourth quadrants (Fig. 2). Two wind and wave conditions occurring at an average frequency of $10 \%$ (Tab. 1) have been chosen for this study.

Table 1: Summary of the chosen scenarios.

\begin{tabular}{|c|c|c|c|c|c|}
\hline Scenario & $\begin{array}{c}\text { Wind Dir } \\
(\mathrm{m} / \mathrm{s})\end{array}$ & $\begin{array}{c}\text { Wind } \\
\text { Speed }\left({ }^{\circ}\right)\end{array}$ & Hs (m) & Tp (s) & $\begin{array}{c}\text { Wave Dir } \\
\left({ }^{\circ}\right)\end{array}$ \\
\hline Libeccio & 225 & 12 & 3.5 & 10 & 225 \\
\hline Maestrale & 300 & 10 & 1.5 & 7 & 300 \\
\hline
\end{tabular}


The numerical simulations, concerning sea current distribution, wave propagation and the sediment particles dispersion, were carried out using the two scenarios, both in presence and in absence of the new harbour structures.

\section{Results and discussion}

\subsection{Fixed stations}

The variation over time of the main parameters and the relations between them are shown in the figures. In particular the temperature, turbidity and chlorophyll $a$ temporal trends found during August and December 2012 and 2013 were compared.

The temperatures showed the stabilization of the water masses inside the harbour area and the low exchange between external and internal waters during 2013, while its variations in 2012 followed the meteomarine and dynamic conditions (Fig. 3). The stability of temperature from October 3 to November 10 as well as from December 5 to 31 was ascribable to winds from the II and III quadrant. Variations during 2013 were due to winds from IV and III quadrant which caused thermic variations up to $5^{\circ} \mathrm{C}$. This process affected both turbidity and chlorophyll $a$ trends: turbidity strongly decreases during 2013 (Fig. 4)

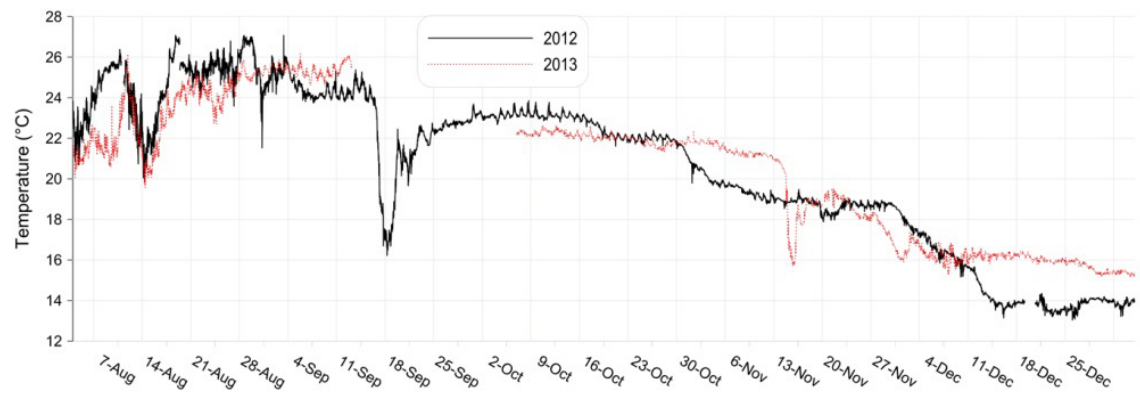

Figure 3: $\quad$ Surface water temperature trends (August-December 2012-2013).

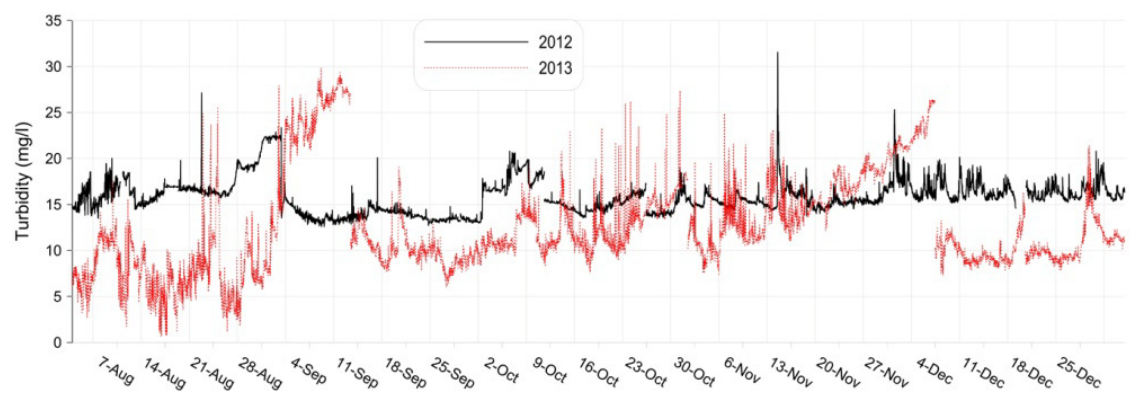

Figure 4: $\quad$ Surface water turbidity trends (August-December 2012-2013). 


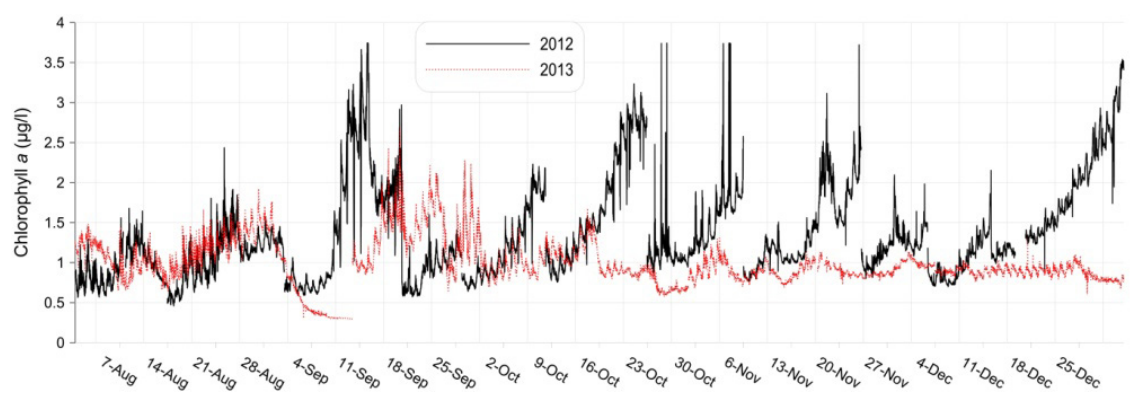

Figure 5: $\quad$ Surface water chlorophyll a trends (August-December 20122013).

because of water masses stabilization; chlorophyll- $a$ showed high concentrations but with more stable trends (Fig. 5).

\subsection{Mathematical models}

In this study the hydrodynamic and wave fields induced by Libeccio and Maestrale conditions are analysed in absence and in presence of the new structures (Fig. 6). In order to assess the impacts of these works on the sea current and wave energy, the velocity intensity and wave height profiles are carried out around the fixed station in two different direction (Fig. 7): one from outside to inside the port entrance (Profile A) and other from the pier where is located the water quality station to harbour breakwater (Profile B). In each graph the sea current and wave energy are compared in absence (blue and solid lines) and in presence (red and dash dot lines) of the new structures.

The Libeccio wind direction caused the presence of clockwise vortex located at the harbour entrance with current velocity greater than $0.0075 \mathrm{~m} / \mathrm{s}$. As a result of the new structures, the southern edge of this eddy didn't reach the pier where the fixed station was installed. Consequently the profile A of the sea current showed a drastic decrease of the velocity intensity passing from $7 \mathrm{~mm} / \mathrm{s}$ (before the harbour modification)s to $3.5 \mathrm{~mm} / \mathrm{s}$ (after the new structures).

Similar results occurred near the fixed station (profile B) where the sea current was lower than those calculated in absence of the Colombo breakwater extension and new Dock Services (from $0.4 \mathrm{~mm} / \mathrm{s}$ to $0.1 \mathrm{~mm} / \mathrm{s}$ ). Inside the harbour the Libeccio conditions induced a counterclockwise vortex with a diameter of about $200 \mathrm{~m}$ and current speed of $2 \mathrm{~mm} / \mathrm{s}$.

The hydrodynamic field produced by Maestrale wind was more intense than the one induced by Libeccio. The Colombo breakwater extension and new Dock Services cause a velocity decrease highlighted in both profiles: from inside to outside the port entrance, where the highest variation was recorded (from $4.2 \mathrm{~cm} / \mathrm{s}$ to $2.5 \mathrm{~cm} / \mathrm{s}$ ), and in proximity of the pier 26 (from $2.5 \mathrm{~cm} / \mathrm{s}$ to $1.5 \mathrm{~cm} / \mathrm{s}$ ). Unlike the Libeccio, the Maestrale wind induced a clockwise vortex inside the harbour area with the same dimension as described in the previous conditions but with current speed greater than $0.01 \mathrm{~m} / \mathrm{s}$. 

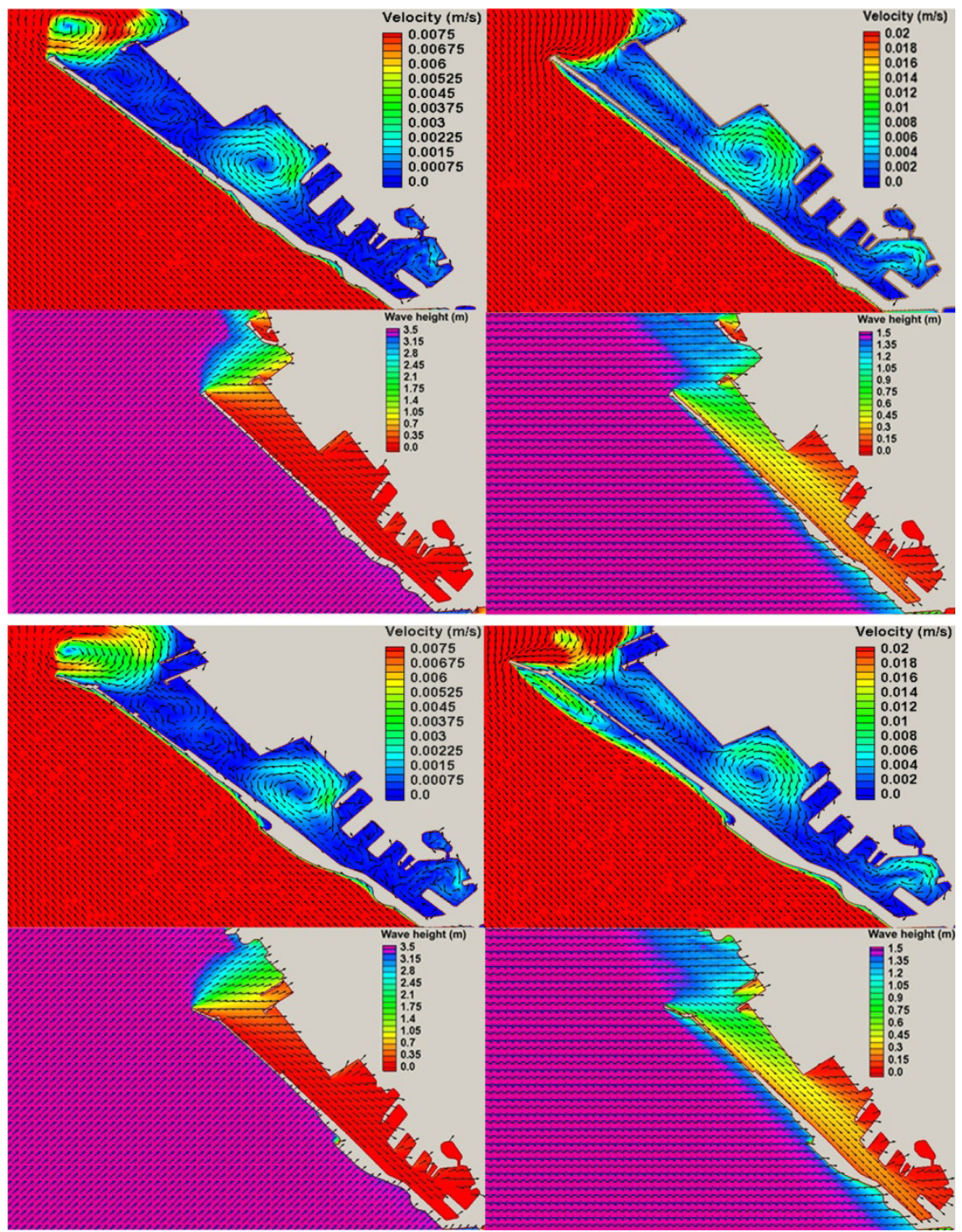

Figure 6: Hydrodynamical and wave fields induced by Libeccio (left) and Maestrale (right) winds inside and around the harbour area. The sea currents are calculated before (above) and after (below) the installation of the new structures. 

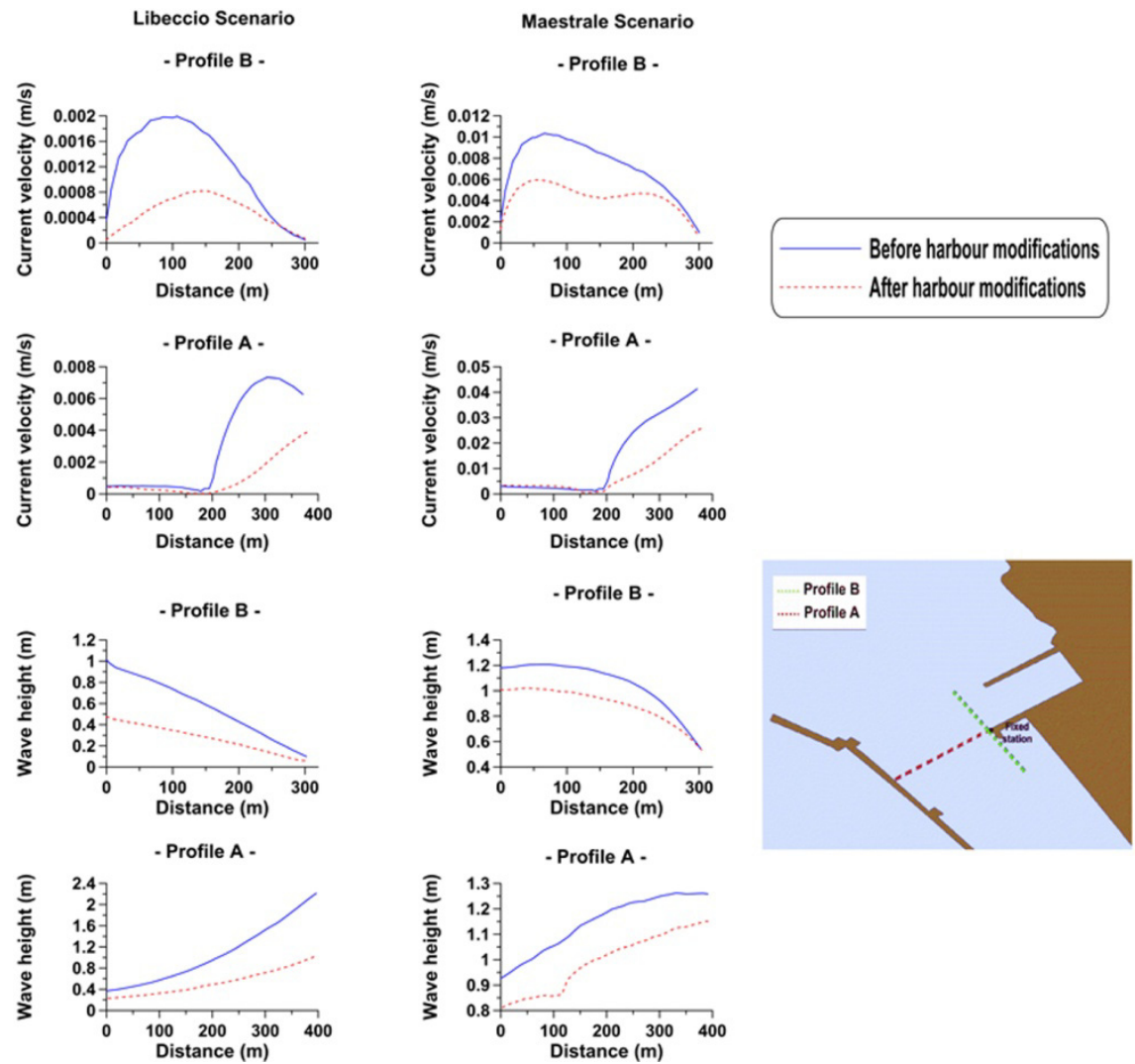

Figure 7: $\quad$ Sea current profiles and wave height profiles.

In both simulated scenarios, the Colombo breakwater extension produced the wave height decrease near the pier where the fixed station was located and in the area between inner and outer harbour. Particularly in the Libeccio conditions near the fixed station the percentage decrease of the wave energy was $52 \%$ and $7.6 \%$ under the Libeccio and Maestrale conditions respectively; while at the port entrance the wave energy reduction was $54.5 \%$ in the Libeccio and $8 \%$ in the Maestrale.

The hydrodynamic and wave fields calculated in the previous scenarios were used to simulate the transport processes applied to sediment particles with median grain size of $0.05 \mathrm{~mm}$ and density of $2650 \mathrm{~kg} / \mathrm{m}^{3}$, released from a point located near the fixed station. Due to the decrease of the current speed and wave energy induced by the new harbour structures, the fraction of settled sediment particles increased (Fig. 8). During the Libeccio event $56 \%$ of the suspended particles inside and around the harbour area settled. In the same area the sedimentation, induced by Maestrale conditions, was lower (32\%) because a high fraction of the suspended matter was spread out of the harbour area, southwards of Civitavecchia port. 


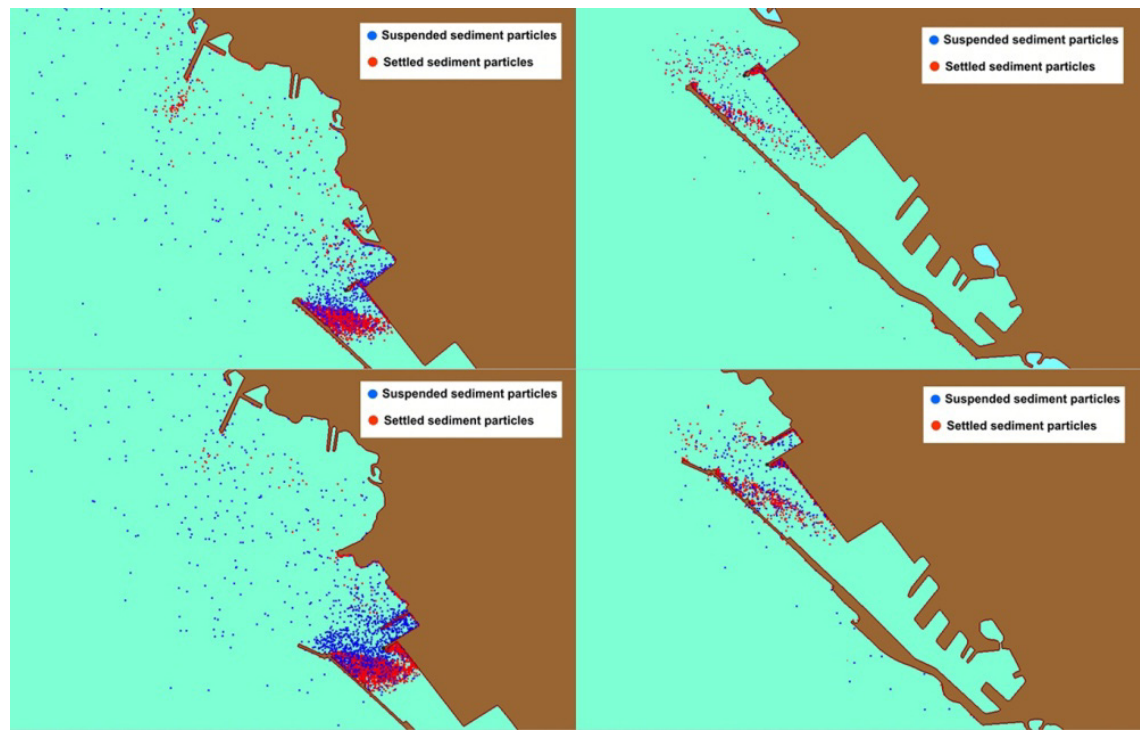

Figure 8: $\quad$ Sediment particles dispersion around and inside harbour generated by Libeccio (left) and Maestrale (right) conditions, before (above) and after (below) the installation of the new harbour structures

\section{Conclusions}

The results of this work show that the extension of the Civitavecchia harbour embankment realized in January 2013 affected dynamics and environmental conditions of the internal water masses. The comparison between 2012 and 2013 turbidity and chlorophyll $a$ trends, measured at the fixed station, shows that the values of the observed parameters present a general decrease due to the attenuation in the hydrodynamic conditions.

The mathematical models support the results obtained by the fixed station time series analyses. The new engineering structures determine the decrease of the hydrodynamic and waves fields inside the harbour, so causing a higher sedimentation of the suspended matter.

The observatory network integrated by the use of mathematical model revealed to be a good approach for monitoring a harbour area.

\section{References}

[1] Sin, Y.M., Wong, M.K., Chou, L.M., Alias, N.B., A study of the heavy metal concentrations of the Singapore River. Environmental Monitoring Assessment, 19, pp. 481-494, 1991.

[2] Goh, B.P.L., \& Chou, L.M., Heavy metals in marine sediments of Singapore. Environmental Monitoring Assessment, 44, pp. 67-80, 1997. 
[3] Zappalà, G., Crisafi, E., Caruso, G., Azzaro, F., Magazzù, G., Coastal monitoring by an advanced technology platform. Proc. Oceanology International 98 - The Global Ocean, Brighton (UK) 10-13 March 1998, I, pp. 69-84, 1998.

[4] Zappalà, G., Alberotanza, L., Crisafi, E., Automatic monitoring on an unmanned offshore platform. Proc. The Marine Technology Society Annual Conference - Ocean Community Conference '98 - Celebrating 1998 International Year of the Ocean, Baltimore (USA) 16-19 November 1998, I, pp. 585-589, 1998.

[5] Zappalà, G., Alberotanza, L., Crisafi, E., Assessment of environmental conditions using automatic monitoring systems. Proc. MTS-IEEE Oceans '99 - Riding the Crest into the 21st Century, Seattle (USA) 13-16 September 1999, II, pp. 796-800, 1999.

[6] Zappalà, G., Caruso, G., \& Crisafi, E., The "SAM" integrated system for coastal monitoring, Proc. of the $4^{\text {th }}$ International Conference on Environmental problems in Coastal Regions, ed. C.A. Brebbia, WIT Press: Southampton, 8, pp. 341-350, 2002.

[7] Zappalà, G., Caruso, G., Azzaro, F., \& Crisafi, E., Integrated environment monitoring from coastal platforms. Proc. $6^{\text {th }}$ International Conference on the Mediterranean Coastal Environment, MEDCOAST 03, ed. E. Ozhan, MEDCOAST, Middle East Technical University: Ankara, 3, pp. 20072018, 2003.

[8] Zappalà, G., A software set for environment monitoring networks. Proc. of the Int. Conf. On Development and Application of Computer Techniques to Environmental Studies X. Envirosoft 2004, eds. G. Latini, G. Passerini, \& C. A. Brebbia, WIT Press: Southampton, pp. 3-12, 2004.

[9] Zappalà, G., Caruso, G., \& Crisafi, E., Coastal pollution monitoring by an automatic multisampler coupled with a fluorescent antibody assay. Proc. of the $5^{\text {th }}$ International Conference on Environmental problems in Coastal Regions, eds. C.A. Brebbia, J.M. Saval Perez, L. Garcia Andion \& Y. Villacampa Esteve, WIT Press: Southampton, 10, pp. 125-133, 2004.

[10] Zappalà, G., Azzaro, F., A new generation of coastal monitoring platforms, Chemistry and Ecology, 20, pp. 387-398, 2004.

[11] Marcelli, M., Di Maio, A., Piermattei, V., Zappalà, G., and Manzella, G., Development of new technologies for the high variability phenomena data acquisition in the MFSTEP-VOS project. Proc. Fourth International Conference on EuroGOOS. Operational Oceanography: Present and Future, eds. H. Dahlin, N.C. Flemming, P. Marchand \& S. E. Petersson, European Commission Publication Office, pp. 184-187, 2006.

[12] Zappalà, G., Marcelli, M., Piermattei, V., Development of a sliding device for extended measurements in coastal waters. WIT Transactions on Ecology and the Environment, eds. D. Prats Rico, C. A. Brebbia, Y. Villacampa Esteve, WIT Press: Southampton, 111, pp. 187-196, 2008.

[13] Zappalà, G., A versatile software-hardware system for environmental data acquisition and transmission. WIT Transactions on Modelling and 
Simulation, eds. C. A. Brebbia \& G. M. Carlomagno, WIT Press: Southampton, 48, pp. 283-294, 2009.

[14] Zappalà, G., Bonamano, S., Madonia, A., Caruso, G., Marcelli, M., Microbiological risk assessment in a coastal marine environment through the use of mathematical models. WIT Transactions on Ecology and the Environment, 164, pp. 3-14, 2012.

[15] Zappalà, G., Caruso, G., Piermattei, V., Bonamano, S., Madonia, Di Cicco, A., Marcelli, M., Integrated Marine Measurements in Civitavecchia, near Rome. WIT Transactions on Modelling and Simulation, 55, pp. 221-235, 2013.

[16] Marcelli, M., Piermattei, V., Zappalà, G., Advances in low cost marine technologies. WIT Transactions on Modelling and Simulation, eds. G.M. Carlomagno \& C.A. Brebbia, WIT Press: Southampton, 51, pp. 497-507, 2011.

[17] Luettich, R.A., Westerink, J.J., \& Scheffner, N.W., ADCIRC: An advanced three-dimensional circulation model for shelves, coasts, and estuaries, Report 1: Theory and methodology of ADCIRC-2DDI and ADCIRC-3DL. Technical Report DRP-92-6, U.S. Army Engineer Research and Development Center: Vicksburg, MS, pp. 1-137, 1992.

[18] Smith, J.M., Sherlock, A.R., \& Resio, D.T., STWAVE: Steady-State Spectral Wave Model user's guide for STWAVE Version 3.0, ERDC/CHL SR-01-01, U.S. Army Engineer Research and Development Center: Vicksburg, MS, 2001.

[19] MacDonald, N. J., Davies, M.H., Zundel, A.K., Howlett, J.D., Lackey, T.C., Demirbilek, Z., \& Gailani, J.Z., PTM: Particle tracking Model; Report 1: Model theory, implementation, and example applications. ERDC/CHL TR-06-20, U.S. Army Engineer Research and Development Center: Vicksburg, MS, 2006.

[20] Galanis, G., Hayes, D., Zodiatis, G., Chu, C.P., Kuo, Y.-H., Kallos, G., Wave height characteristics in the Mediterranean Sea by means of numerical modeling, satellite data, statistical and geometrical techniques. Marine Geophysical Research, 33, pp. 1-15, 2012. 